RESEARCH REPORT

\title{
PREVALENCE OF MUSCULOSKELETAL DISORDERS AMONG THE CARE GIVERS OF PHYSICALLY DISABLED CHILDREN
}

\begin{abstract}
BACKGROUND AND AIMS

It has been estimated that $14-17 \%$ of the cases referred to primary care consultations are related to musculoskeletal disorders. The study was aimed to determine prevalence of Work Related Musculoskeletal disorder among care givers of physically handicapped children.
\end{abstract}

\section{METHOD}

The study includes a sample size of 187 caregivers of physically handicapped children. Two differently self-designed questionnaires were used to gather information from the clinician and the parents separately. The data was collected only once from the participants. It was assured that the data would be used only for research purpose, prior consent was taken before administering the questionnaire.

\section{RESULTS}

The result showed that $n=187$ participants that were involved in the process of care giving to the physically handicapped children. Prevalence of musculoskeletal disorder was found equally high among clinicians and parents. However, no association $p>0.05$ between the age and the type of WMSDs was observed.

\section{CONCLUSIONS}

The study concluded that Work Related Musculoskeletal disorders were prevalent among the care givers of physical handicapped children and was found to be equally affecting the parents and the clinicians.

\section{KEYWORDS}

Musculoskeletal Disease, Physical Therapist, Occupational Therapist, Low back pain, Thoracic Outlet Syndrome.

\author{
Shujaat Hussain Memon \\ Principal, Assistant Professor \\ Hyderabad Institute of medical and Allied \\ Sciences \\ shmemon88@gmail.com

\section{Dr.Fiza Memon} \\ Senior Lecturer \\ Hyderabad Institute of medical and Allied \\ Sciences \\ fiza.memon@gmail.com
}

[Memon SH , Memon F. Prevalence Of Musculoskeletal Disorders Among The Care Givers Of Physically Disabled Children. Pak. j. rehabil. 2018:7(2);19-24 ] 


\section{INTRODUCTION}

Globally the prevalence of musculoskeletal diseases has steadily been growing during the course of last decade leading to an approximately $20 \%$ increase from the year 2006 to $2016^{1}$.It has also been estimated that $14-17 \%$ of the cases referred to primary care consultations are related to Musculoskeletal disorders ${ }^{2-3}$. Many of these conditions are self-managed but other required treatments while some may develop into a chronic condition that greatly impede the quality of life and reduces activity of daily living in the long run ${ }^{4}$. According to the data provided by labor bureau of United States in 2013 work related musculoskeletal disorders in health care setting alone is costing more than 2 million loss of workdays every year while figuring approximately a liability \$1 billion annually in terms of worker compensation cost $^{5}$. Work Related Musculoskeletal Disorders (WRMDs) are listed as non-contagious disease and disorders undergo in the worker on the musculoskeletal, peripheral nerves, and neurovascular systems due to continuous revelation to workplace threats WRMDs are known to be a leading occupational problem among Physical Therapist and Occupational Therapist but the same also affects the life of all those care givers that performs strenuous physical activities and repetitive performance of the task in the management of the physically handicapped patient'. According to the study conducted by Islam MS et al in 2015 it was observed that low back pain is among the most common Work related musculoskeletal disorder with the prevalence of around $84 \%$ followed by pain in the upper back and neck that is found to be prevalent in $70 \%$ and $65 \%$ of the cases respecrively?. A study conducted in the year 2015 mainly involving the mothers of physically handicapped children the most reported health care problems that was highlighted involved musculoskeletal pain at the level of lower back and neck followed by reduced functional ability recorded on Gross Motor Functional Classification Scale $(G M F C S)^{8}$. Moreover it was also highlighted in the another study that the most common clinical setups where the incidences of having the work related musculoskeletal disorders are high mainly involved three specialized health care department that are musculoskeletal out-patients physical therapy setups where the estimated incidence of having the WMSDs is $31 \%$ followed by Neurological Rehabilitation department $14 \%$ and elderly care department $12 \%$. An interesting finding were observed in a study conducted by Liao JC et al in 2016 in which the researchers had compared the risk of developing the incidence of the new onset of work related musculoskeletal spinal disorders among three health care professionals that are Physical therapist, Occupational therapist and Pharmacist and it was observed that the probability of having Spine related musculoskeletal disease during the period of 12 years are high among physical therapy professional 0.5 followed by Occupational therapist 0.4 and pharmacist $0.25^{10}$. Hence the present study is aimed to identify the prevalence of Work related Musculoskeletal Disorders (WMSDs) among the care givers of physically disabled children's of Karachi, Pakistan population.

\section{METHODOLOGY}

\section{Study Design}

A Cross-Sectional Study was conducted

\section{Sampling Technique}

Convenient Sampling Technique was used for the recruitment of participant.

\section{Study Setting}

The study was conducted in the clinical settings of different health care institutions of Karachi that were involved in the management of physically disabled children like cerebral palsy, Down syndrome etc.

\section{DATA COLLECTION PROCEDURE}

The study included a sample size of 184 caregivers of physically handicapped children; including both the parents and the clinicians. Two differently self-designed questionnaires were used to gather information from the clinician and the parents separately. The questionnaires that were filled by the parents mainly involved question related to the location and the mechanism of pain like low back, muscular, shoulder, neck and mid thoracic pain. Whereas the questions related to the diagnosed musculoskeletal conditions like Thoracic Outlet Syndrome, Myofascial pain Syndrome, Fibromyalgia, Tendonitis, Carpal Tunnel Syndrome and others that participants' wants to highlight were the part of the questionnaire that were administered by the clinicians along with the questions that were asked from the parents. Besides that the questions related to the demographic information such as age, gender, clinical experience, were also the part of the questionnaire. The data was collected only once from the participants and all measures had been taken to maintain the ethical consideration of confidentiality and non-partiality. Besides that all the participants were informed that the data would be used only for research purpose and the prior consent was taken before administering the questionnaire.

\section{Inclusion and Exclusion Criteria}

Inclusion criteria includes clinician and parents that were involves in the process of care giving to children diagnosed with the conditions like down syndrome ${ }^{11}$, cerebral palsy ${ }^{12}$, Klinefelter syndrome, Autism Spectrum Disorder ${ }^{13}$ and any other disorder that made the independent movement of the children difficult without their support. Moreover the 
age of the parents as care givers were in between 20 to 40 years and as clinician they were either a Physical therapist or an occupational therapist of the same age group as was fixed for the parents, whereas all those care givers that had already diagnosed systemic diseases like COPD, heart disease ${ }^{14}$, fracture ${ }^{15}$ or any other disability that made them difficult to involve in the process of care giving were excluded from the study.

\section{Data Collection Tool Self-Designed Questionnaire}

Self-designed questionnaire was used in this study as a data collection tool consisting 33 items. Demographic data of caregiver included name, age, gender (male and female), marital status (unmarried, married, separate, divorced, widow/widower), number of children, number of handicap children, height and weight of the caregiver, BMl of the caregiver and age of handicap children. Other components of questionnaire included, frequency of exercise performed, type of disability of child ( CP, lower extremity deformity, spina bifida, polio, juvenile idiopathic arthritis, down syndrome, rickets ) level of co-operation of child ( non-cooperative, full or partial co-operative), type of disability in mother (LBP, TOS, MPS, FMS, tendinitis, CTS or any other), relapse of WMSD, most affected region due to pain, pain severity, duration since onset, duration of symptoms and frequency of occurrence in neck, shoulder, upper back, lower back, elbow, hands and wrist, thigh, knee, feet and ankle. Other questions were, affecting work performance (mild, moderate, severe affected or unable to work), seeking treatment for musculoskeletal pains and use of any supportive device while working. All of above questions were asked from the caregiver to gather information about musculoskeletal pains

\section{Ethical Consideration}

Ethical approval has been taken from the institutional review board of the concerned hospital settings before conducting the research. Moreover, an informed consent was given to the participants before enrolling them in the study.

\section{RESULTS}

The result shows that out of $n=187$ participants that were involves in the process of care giving to the physically handicapped children $n=95$ were clinicians out of which $n=47$ were Physical Therapist (PT) and $n=48$ were Occupational Therapist (OT) and $n=92$ were parents that includes both male and female $n=46$ were male and $n=46$ were female.

Further out of $n=47$ physical therapist $n=30$ were female and $n=17$ were male whereas in occupational therapist as clinician all were females participants (Table 1)

\begin{tabular}{|l|c|c|c|c|c|}
\multicolumn{5}{|c|}{ Table 1. Frequency of male and female participants } \\
in clinical group
\end{tabular}

The cross tab analysis of the data had revealed that Work related Musculoskeletal Diseases (WMSDs) were found to be prevalent among both the clinicians and the parents involved in the care giving of physically handicapped children where $55 \%$ of the clinicians included in the study complained for low back pain, $25 \%$ were had a diagnosed carpal tunnel syndrome, $15 \%$ complained for thoracic outlet syndrome and whereas $2.5 \%$ were diagnosed with tendonitis and fibromyalgia (figure 1).

\section{Figure 1. Illustration of Cross Tab Analysis}

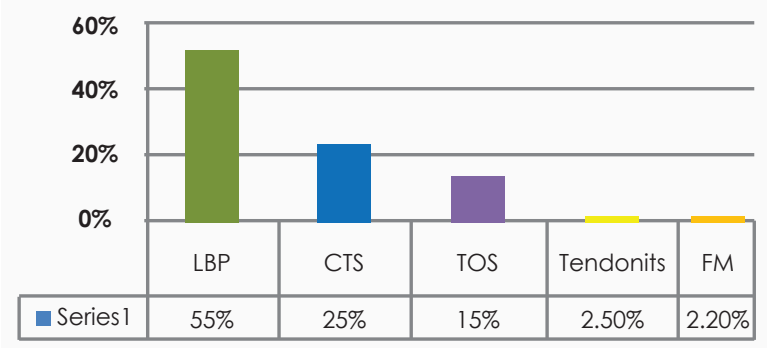

Further analysis had revealed that the most prevalent type of WMSDs that was prevalent among the PTs were Low back pain followed by TOS and Tendonitis (table 2)

\begin{tabular}{|c|c|c|c|}
\hline \multicolumn{4}{|c|}{ Table 2. Common MSDs among PTs } \\
\hline Variables & LBP & TOSQ & Tendonitis \\
\hline N & 23 & 15 & 9 \\
\hline \%age & $48.9 \%$ & $31.91 \%$ & $19.1 \%$ \\
\hline
\end{tabular}

Whereas among Occupational therapist the most prevalent WMSDs was found to be Carpal Tunnel followed by low back pain and Fibromyalgia Pain Syndrome (table 3)

\begin{tabular}{|c|c|c|c|}
\hline \multicolumn{4}{|c|}{ Table 3. Common } \\
\hline Variables & CTS & LBP & FMS \\
\hline N & 25 & 20 & 3 \\
\hline \%age & $52.08 \%$ & $41.66 \%$ & $2.74 \%$ \\
\hline
\end{tabular}

The analysis of the prevalence of WMSDs among the parent caregiver revealed that most of the parents were suffering from Low back and Shoulder pain followed by neck and mid thoracic pain (Figure 2) 
Figure 2. Illustration of Cross Tab Analysis among parents

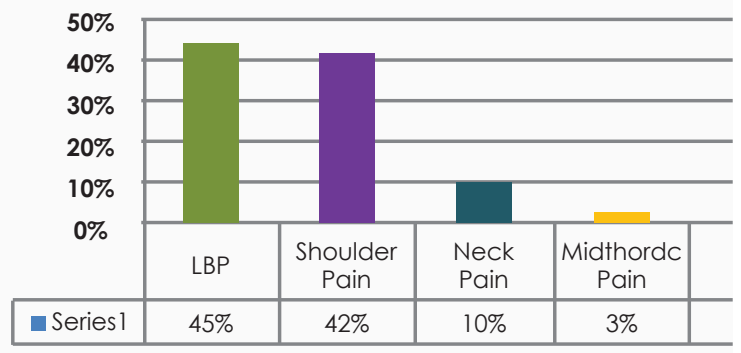

Chi-square analysis test was further applied to determine the association between the age and the type of WMSDs that showed no association $\mathrm{p}>0.05$ that suggested work related musculoskeletal disorder was independent to the age of the participants (table 4).

\begin{tabular}{|l|c|c|c|c|c|}
\hline $\begin{array}{r}\text { Table 4. Chi-square Analysis depicting association } \\
\text { between age and WMSDs among Clinicians }\end{array}$ \\
\hline Variables & \multicolumn{5}{|c|}{ Age in Years } \\
\hline WMSDs & $20-25$ & $26-30$ & $31-35$ & $36-40$ & P-value \\
\hline LBP & 12 & 10 & 10 & 11 & \\
\hline CTS & 10 & 5 & 5 & 5 & \\
\hline TOS & 5 & 3 & 3 & 4 & $>$ \\
\hline Tendonitis & 3 & 3 & 2 & 1 & \\
\hline FMS & 1 & 2 & 0 & 0 & \\
\hline
\end{tabular}

The chi-square association between the age of the parents and the frequency of the location of WMSDs pain had also shown the similar findings p>0.05 that further confirmed that work related musculoskeletal diseases were found to be independent from the age of the participants (table 5)

\begin{tabular}{|c|c|c|c|c|c|}
\hline \multicolumn{6}{|c|}{$\begin{array}{l}\text { Table } 5 . \text { Chi-square Analysis depicting association } \\
\text { between age and WMSDs among parents }\end{array}$} \\
\hline Variables & \multicolumn{5}{|c|}{ Age in Years } \\
\hline WMSDs & $20-25$ & $26-30$ & $31-35$ & $36-40$ & P-value \\
\hline LBP & 19 & 14 & 10 & 1 & \multirow{4}{*}{$>0.05$} \\
\hline $\begin{array}{l}\text { Shoulder } \\
\text { Pain }\end{array}$ & 10 & 10 & 9 & 7 & \\
\hline Neck Pain & 2 & 2 & 3 & 1 & \\
\hline $\begin{array}{c}\text { Mid } \\
\text { Thoradic } \\
\text { Pain }\end{array}$ & 1 & 0 & 2 & 1 & \\
\hline
\end{tabular}

\section{DISCUSSION}

The results of the study had revealed that Work related musculoskeletal disorders were the most prevalent form of occupational diseases that were prevalent among the subjects involved in the management of the physically disabled children. Among various types of WMSDs the most common that affects the clinician in the Physical Therapy setups was the low back pain that affects almost $48.9 \%$ of the Physical therapist involved in the clinical settings for the management of Physically disabled Children the same form of result was also revealed by Liao et al in a study conducted in the year 2016 in which it was concluded that Spine related Musculoskeletal disease were incidentally high among Physical Therapist professional in comparison to Occupational Therapist and Pharmacist ${ }^{10}$ whereas the age of the onset in the same study was estimated to be 24 years that was the case with our study as well in which it was observed that the age of the onset of Low back pain related to WMSDs was found to be in between $20-25$ years in both the group that were parents and clinician. However, the study conducted by Tinubu et al and King et al it was concluded that the onset of WMSD were mostly found in the age group of $\leq 30$ years ${ }^{16-17}$. The result of our study had also revealed that among parents involved in care giving the second most prevalent form of WMSDs was shoulder pain as the repetitive movement at the level of shoulder during lifting and shifting of the patient pulled shoulder muscle that may become a source of musculoskeletal pain if proper technique of lifting and ergogenic aids were not adequately applied the same was the finding of S.D. Choi and K. Brings5 review article in which they had suggested that proper utilization of Ergonomic intervention strategies as recommended by Occupational Safety and Health Administration (OSHA) ${ }^{18-19}$ reduces the incidences of work related injuries among the patients and improves the patient safety parameters. Multiple Studies also supported the findings that engineering based devices if administered by the health related professionals during the shifting and lifting of patient reduces the chances of new onsets of musculoskeletal pain and disabilities ${ }^{20-21}$. A studies conducted on nurses revealed that ergonomically administered intervention strategies when applied by nurses in the management of bariatric patients reduces the risk of injury among nurses 22 . The present study had also revealed that among Occupational Therapist the most common type of musculoskeletal disorder was Carpal Tunnel Syndrome that was found to be prevalent in $52.08 \%$ of the cases the findings suggest that as the mechanism of occupational musculoskeletal disease depends on the nature of the performance of the task justifies the high prevalence of CTS among occupational therapist as the main task of OTs were highly based on improving the functional limitation of patients and managing 
the fine dexterity among the handicapped children the repetitive strenuous activity at the level of wrist may cause high incidence and prevalence of CTS among Occupational therapist. Finally, the results of our study revealed no association between age and the prevalence and onset of work related occupational diseases the findings suggest that as the occupational MSDs were mainly associated with the level of strenuous repetitive activities that were performed by the individual and has no connection with the age the findings were similar to the findings of Alghadir A et al in which it was concluded that age of the respondent was not directly linked with the WMSDs23 however gender and occupation had a direct link as female suffer more than the male population and occupational with greater strenuous activities had a greater likelihood of developing WMSDs ${ }^{23-25}$. The study had some limitations as the data was based from those institutions of Karachi, Pakistan that are primarily involves in the management of children's with disabilities and the Physical and Occupational therapist working in those institutions only thus may limits the generalizability of results on greater scale as the bigger tertiary care hospitals of Karachi were not the part of the data collection strategies further due to lack of funding and transportation facilities a sample of 187 only was taken that may increases the chances of statistical errors moreover due to lack of awareness among the local population of Karachi regarding the importance of research and evidence there were few questionnaires that were not properly filled that causes the loss of data at few intervals. However our study has some strengths as well as the study was first of its type in Karachi, Pakistan that had highlighted the prevalence of WMSDs among the parents and professionals of physically handicapped children. Further the study will open a new door for future researches that may indeed found to be helpful to get greater evidence on larger scale.

\section{CONCLUSION}

The study concluded that Work Related musculoskeletal disorders were prevalent among the care givers of physical handicapped children and was found to be equally affecting the parents and the clinicians. It was also observed from the data that age of the respondents had no association with the onset of WMSDs and the repetitive strenuous activities were the cause of developing the disorder among the care givers of physically handicapped children. The researcher recommended that more studies are required to be conducted in this regard on larger effects size so that the generalizability of the findings could be better interpreted on larger scale.

\section{REFERENCES}

[1] Bornhöft L, Larsson ME, Nordeman L, Eggertsen $R$, Thorn J. Health effects of direct triaging to physiotherapists in primary care for patients with musculoskeletal disorders: a pragmatic randomized controlled trial. TherAdvMusculoskelet Dis. 2019;1 1:1759720X19827504.

[2] Mansfield KE, Sim J, Jordan JL, Jordan KP. A systematic review and meta-analysis of the prevalence of chronic widespread pain in the general population. Pain. 2016;157(1):55.

[3] Månsson J, Nilsson G, Strender LE, Björkelund C. Reasons for encounters, investigations, referrals, diagnoses and treatments in general practice in Sweden-a multicentre pilot study using electronic patient records. Eur J Gen Pract. 2011;17(2):87-94.

[4] Schoenfisch AL, Lipscomb HJ, Pompeii LA, Myers DJ, Dement JM. Musculoskeletal injuries among hospital patient care staff before and after implementation of patient lift and transfer equipment. Scand J Work Environ Health2013:27-36.

[5] Choi SD, Brings K. Work-related musculoskeletal risks associated with nurses and nursing assistants handling overweight and obese patients: A literature review. Work. 2016;53(2):439-48.

[6] Yasobant S, Rajkumar P. Work-related musculoskeletal disorders among health care professionals: A cross-sectional assessment of risk factors in a tertiary hospital, India. Indian J. Occup. Environ. Med. 2014;18(2):75.

[7] Islam $M$, Habib $M$, Hafez $M$, Nahar $N$, Lindstrom-Hazel D, Rahman M. Musculoskeletal complaints among physiotherapy and occupational therapy rehabilitation professionals in Bangladesh. Work. 2015 50(3):379-86.

[8] Shah ZA, Darain H. Association of age, weight and gender with work related low back pain among clinical physical therapists in Pakistan.

[9] Greiner BA, Nolan S, Hogan DA. Work-Related Upper Limb Symptoms in Hand-Intensive Health Care Occupations: A Cross-Sectional Study With a Health and Safety Perspective. Physther. 2018:99(1):62-73.

[10] Liao JC, Ho CH, Chiu HY, Wang YL, Kuo LC, Liu C, Wang JJ, Lim SW, Kuo JR. Physiotherapists working in clinics have increased risk for new-onset spine disorders: a 12-year population-based study. Medicine. 2016:95(32).

[1 1] Prasher VP, Janicki MP, editors. Physical Health of Adults with Intellectual and Developmental Disabilities. Springer; 2018.

[12] Paduch DA, Ryan CT. Klinefelter Syndrome: Early Treatment of the Adolescent Is Warranted. InBiennial Review of Infertility 2015 (pp. 203-211). Springer, Cham.

[13] Claus M, Kimbel R, Spahn D, Dudenhöffer S, Rose DM, Letzel S. Prevalence and influencing 
factors of chronic back pain among staff at special schools with multiple and severely handicapped children in Germany: results of a cross-sectional study. BMC Musculoskeletdisord. 2014;15(1):55.

[14] Claus M, Adams J, Kimbel R, Letzel S, Rose DM. How can the health situation and well-being of staff at German schools for the severely handicapped be improved?. Int Arch Occup Environ Health. $2016 ; 89(3): 503-11$.

[15] Silva LG, Silva MC. Working and health conditions of preschool teachers of the public school network of Pelotas, State of Rio Grande do Sul, Brazil.

Ciencia\&saudecoletiva. 2013;18(11):3137-46.

[16] Tinubu BM, Mbada CE, Oyeyemi AL, Fabunmi AA. Work-related musculoskeletal disorders among nurses in Ibadan, South-west Nigeria: a cross-sectional survey. BMC Musculoskeletdisord. $2010 ; 11(1): 12$.

[17] King P, Huddleston W, Darragh AR. Work-related musculoskeletal disorders and injuries: differences among older and younger occupational and physical therapists. J OccupRehabil. 2009;19(3):274-83.

[18] Vieira ER, Svoboda S, Belniak A, Brunt D, Rose-St Prix C, Roberts L, da Costa BR. Work-related musculoskeletal disorders among physical therapists: an online survey. DisabilRehabil. 2016;38(6):552-7.

[19] Bae YH, Min KS. Associations between work-related musculoskeletal disorders, quality of life, and workplace stress in physical therapists. Industrial health. 2016;54(4):347-53.
[20] Sultan-Taïeb H, Parent-Lamarche A, Gaillard A, Stock S, Nicolakakis N, Hong QN, Vezina $M$, Coulibaly $Y$, Vézina N, Berthelette D. Economic evaluations of ergonomic interventions preventing work-related musculoskeletal disorders: a systematic review of organizational-level interventions. BMC public health. 2017;17(1):935.

[21] Nath ND, Akhavian R, Behzadan AH. Ergonomic analysis of construction worker's body postures using wearable mobile sensors. ApplErgon. 2017 Jul 1;62:107-17.

[22] Elsherbeny EE, Elhadidy SS, El-Masry R, El-Bahnasawy AS. Prevalence and associated factors of musculoskeletal complaints among nurses of Mansoura University children hospital. Egypt. J. Occup. Med. 2018;42(2):151-66.

[23] Alghadir A, Zafar H, labal ZA. Work-related musculoskeletal disorders among dental professionals in Saudi Arabia. J PhysTher Sci. 2015;27(4):1107-12.

[24] Feng B, Liang Q, Wang Y, Andersen LL, Szeto G. Prevalence of work-related musculoskeletal symptoms of the neck and upper extremity among dentists in China. BMJ open. 2014;4(12):e006451.

[25] lqbal Z, Alghadir A. Prevalence of work-related musculoskeletal disorders among physical therapists. Med Pr. 2015;66(4):459-69. 